\title{
Select geotechnical properties of a lime stabilized expansive soil amended with bagasse ash and coconut shell powder
}

\author{
Jijo James ${ }^{1}$, P. Kasinatha Pandian² \\ ${ }^{1}$ Tagore Engineering College, Chennai, India \\ Department of Civil Engineering \\ ${ }^{2}$ Karpaga Vinayaga College of Engineering and Technology, Kanchipuram, India \\ Department of Civil Engineering \\ e-mail: jijothegreat@gmail.com, pknp2020@gmail.com
}

\begin{abstract}
Lime stabilization has been and still is one of the most preferred methods for stabilization of expansive soils. However, in the recent times, utilization of solid waste materials in soil stabilization has gained prominence as an effective means to manage wastes generated from various sources. In this work, an attempt has been made to utilize waste materials from two sources as auxiliary additives to lime in the stabilization of an expansive soil. Bagasse ash (BA), a waste by-product from the sugar industry and Coconut shell powder (CSP), a processed waste obtained from left over coconut shells of oil extraction industry were used as auxiliary additives. An expansive soil obtained from a local field was subjected to chemical, mineral, microstructural and geotechnical characterization in the laboratory and stabilized using $3 \%$ lime. The waste materials were subjected to chemical, mineral and microstructural characterization. The stabilization process was amended with four different contents viz. $0.25 \%, 0.5 \%, 1 \%$ and $2 \%$ of BA and CSP separately and the effect of the amendment was studied on the unconfined compressive strength (UCS), plasticity, swell-shrink and microstructural characteristics of the expansive soil. The results of the study indicated that BA amendment of lime stabilization performed better than CSP in improving the UCS, plasticity, swell-shrink and microstructure of the lime stabilized expansive soil.
\end{abstract}

Key words: Lime Stabilization, Bagasse Ash, Coconut Shell Powder, Plasticity, Swell-Shrink, UCS

\section{Introduction}

Soil stabilization may be defined as the beneficial modification of the engineering behaviour of problematic soils to make them suitable for engineering and infrastructural applications. Lime and cement have been the most common stabilizers adopted for improving poor soils. Lime stabilization has been the preferred method for improvement of high plastic clays and expansive soils due to the fact that effectiveness of cement stabilization becomes marginal for high plastic clays [1]. Lime stabilization has been extensively studied in mitigating the disastrous effects of swelling soils. Solid waste stabilization of problematic soils has been attempted by several researchers as a means for putting to use the huge quantities of wastes generated from various sources for beneficial use. However, it has been found that 
effectiveness of solid wastes and lime stabilization is magnified by adopting the solid wastes in combination with primary stabilizers like lime and cement [2]. Several solid wastes have been investigated in recent times with varying degrees of depth, in soil engineering. Two such solid wastes are sugarcane bagasse ash (BA) and coconut shell powder (CSP). The former has been fairly investigated for its potential in soil stabilization whereas the latter has not been afforded the same level of investigation in soil stabilization. Utilization of BA in stabilization of soil, stabilized earth blocks, sintered earth blocks and landfill liners have been investigated by several researchers both as a standalone stabilizer [3-7] as well as in combination with lime and cement [8-13]. CSP on the other hand, has been rarely adopted in soil stabilization activities with only a few investigations reporting its use [14-16]. In this investigation, an effort has been made to compare the performances of these two solid wastes adopted as auxiliary additives to lime in stabilization of an expansive soil in improving its unconfined compressive strength (UCS), plasticity, swell-shrink and microstructural characteristics.

\section{Materials and Methods}

This section describes the various materials that were adopted in this work and the methodology adopted in going about the investigation.

\subsection{Virgin expansive soil}

The virgin soil was collected from Tiruvallur District of Tamil Nadu, India. The soil was tested in the laboratory for its various geotechnical properties. Table 1 shows the geotechnical properties of the soil as determined in the laboratory. The soil was also subjected to chemical, mineral and microstructural characterization. The mineralogy of the soil revealed the presence of montmorillonite, quartz, moganite, magnetite and cristobalite among others. The microstructure shows aggregations of platy clay particles as seen in Figure 1.

\subsection{Lime}

Laboratory grade hydrated lime was adopted in stabilizing the virgin expansive soil. The laboratory grade hydraulic lime supplied by M/s. Nice Chemicals India Pvt. Ltd. was adopted in this investigation. The laboratory grade lime was not subjected to any preparation and was used as available from the packaged containers supplied by the manufacturer. Adoption of laboratory grade lime enabled better control over the results due to much lesser variation in the quality and composition of the lime. The mineralogy of lime indicated calcium hydroxide which was obvious and expected result of the analysis. The microstructure (Figure 1) showed that lime had a very fine particle nature. 
Table 1: Properties of Soil

\begin{tabular}{|l|l|}
\hline Property & Value \\
\hline Liquid Limit & $68 \%$ \\
\hline Plastic Limit & $27 \%$ \\
\hline Plasticity Index & $41 \%$ \\
\hline Shrinkage Limit & $10 \%$ \\
\hline Specific Gravity & 2.76 \\
\hline \%Gravel & 0 \\
\hline$\%$ Sand & 2.5 \\
\hline \%Silt & 60.5 \\
\hline \%Clay & 37 \\
\hline MDD & $15.3 \mathrm{kN} / \mathrm{m}^{3}$ \\
\hline OMC & $25 \%$ \\
\hline UCS & $115.8 \mathrm{kPa}$ \\
\hline Free Swell Index & $100 \%$ \\
\hline Soil classification & $\mathrm{CH}$ \\
\hline Degree of Expansion & $\mathrm{High}$ \\
\hline Degree of Severity & $\mathrm{Critical}$ \\
\hline
\end{tabular}

\subsection{Solid wastes}

The solid wastes adopted in this investigation include BA and CSP. BA was collected from M/s. Thirutthani Sugar Mills Pvt. Ltd., Arakkonam, Tamil Nadu, India. CSP was obtained from a small-scale manufacturer involved in processing and grinding of coconut shells based in Pollachi, Tamil Nadu, India. BA was cleaned, crushed, pulverized and sieved through Bureau of Indian Standards (BIS) 300-micron sieve whereas CSP was sieved through BIS 75micron sieve for preparation. The former did not yield much fines on sieving through 75micron sieve. The solid waste materials were also subjected to chemical, mineral and microstructural characterization. Table 2 gives the chemical composition of the various materials adopted in the study. The microstructure of the materials used in the study is shown in Figure 1 along with other materials. The mineralogy of the materials used in the study is given in Figure 2. The mineralogy of BA revealed the presence of cristobalite, quartz and calcium carbonate whereas the mineralogy of CSP revealed the presence of quartz, cristobalite and microcline. Others have reported the presence of quartz, cristobalite, calcite, calcium phosphate, mullite, iron oxide among others in BA [17-20]. The microstructure of BA revealed the presence of bulky grains as well as flakes of burnt bagasse. A comparison of microstructure of BA from various investigations also concluded that BA consisted of both organic as well as inorganic fractions [21]. The microstructure of CSP revealed fine grained 
particles. Aggregation and flocculation of particles was clearly seen. Both platy as well as bulky particle shapes were visible.

Table 2: Chemical Composition of Materials

\begin{tabular}{|l|c|c|c|c|}
\hline Component (\%) & Soil & Lime & BA & CSP \\
\hline $\mathrm{Al}_{2} \mathrm{O}_{3}$ & 18.818 & 0.053 & 0.281 & 3.007 \\
\hline $\mathrm{CaO}$ & 2.297 & 72.767 & 2.071 & 2.041 \\
\hline $\mathrm{Fe}_{2} \mathrm{O}_{3}$ & 7.484 & 0.037 & 5.217 & 6.017 \\
\hline $\mathrm{K}_{2} \mathrm{O}$ & 2.288 & 0.003 & 3.745 & 3.221 \\
\hline $\mathrm{MgO}$ & 1.737 & 14.604 & 0.908 & 0.948 \\
\hline $\mathrm{MnO}$ & 0.035 & 0.004 & 0.038 & 0.090 \\
\hline $\mathrm{Na}_{2} \mathrm{O}$ & 1.415 & 0.047 & 0.012 & 0.243 \\
\hline $\mathrm{P}_{2} \mathrm{O}_{5}$ & 0.043 & 0.005 & 1.034 & 0.315 \\
\hline $\mathrm{SiO}_{2}$ & 63.615 & 0.245 & 35.168 & 20.592 \\
\hline $\mathrm{TiO}_{2}$ & 0.876 & 0.003 & 0.021 & 0.195 \\
\hline $\mathrm{SO}_{3}$ & 0.207 & 0.048 & 0.027 & 0.031 \\
\hline
\end{tabular}

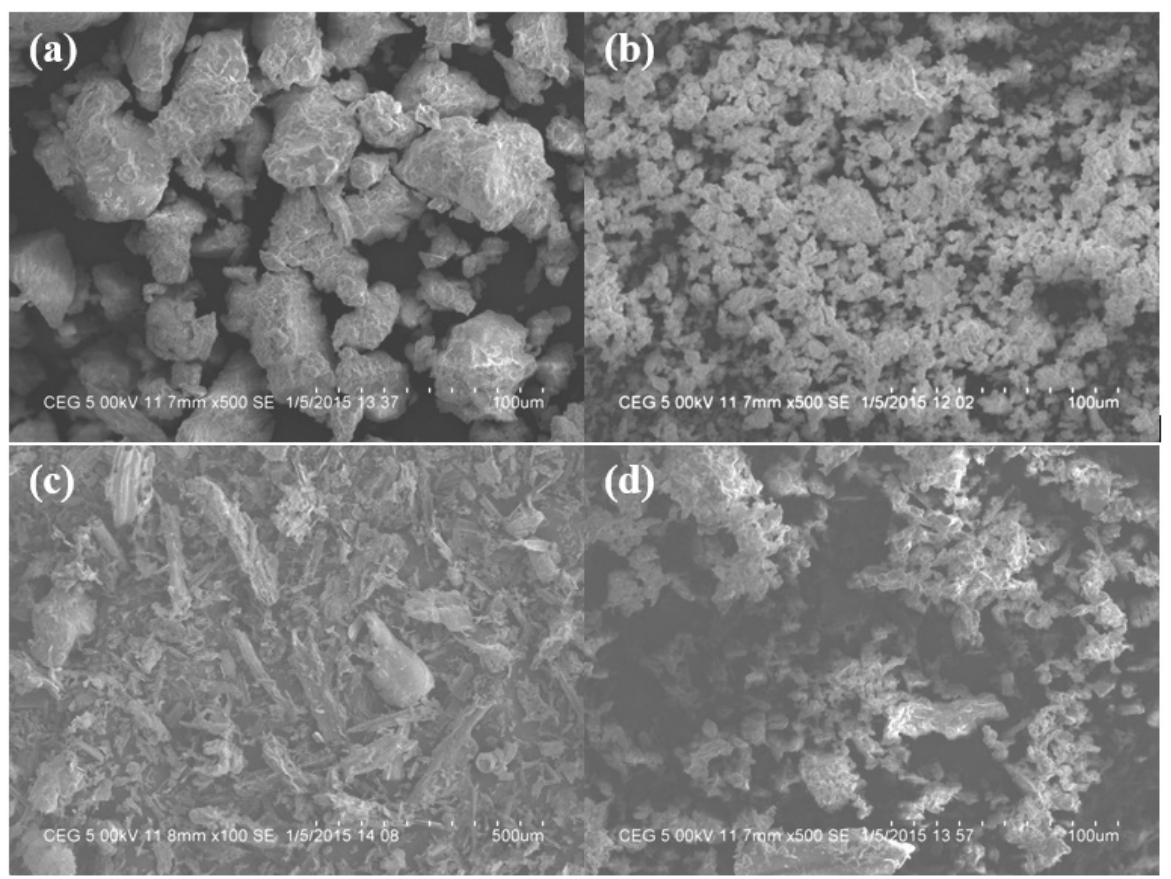

Figure 1: Microstructure of (a) Soil (b) Lime (c) BA (d) CSP 

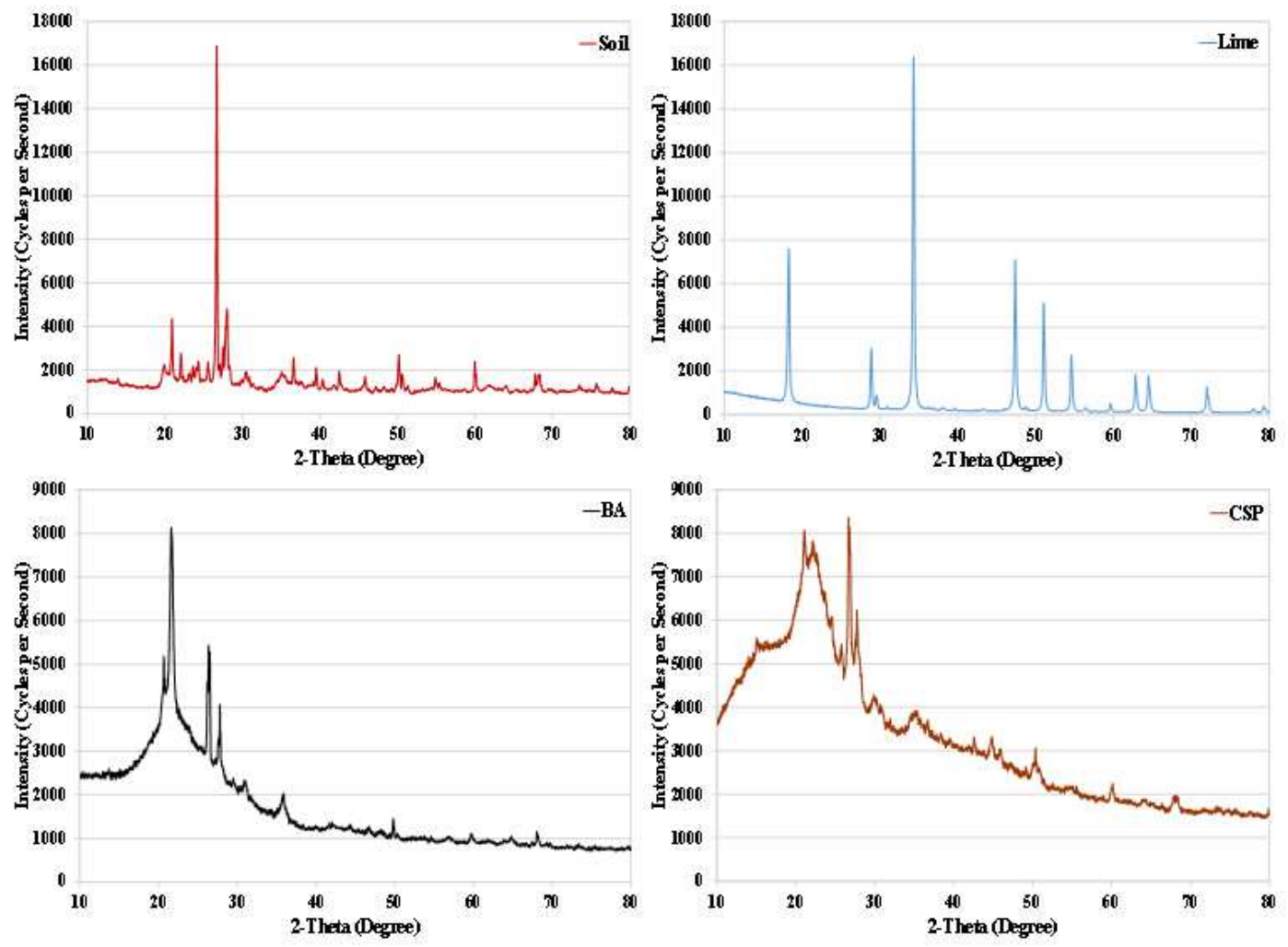

Figure 2: Mineralogy of Soil, Lime, BA and CSP

\subsection{Methodology}

The virgin soil was prepared in the laboratory in accordance with IS 2720: Part 1 [22]. It was subjected to geotechnical characterization that included liquid and plastic limit done in accordance with IS2720:Part 5 [23], shrinkage limit done in accordance with IS2720:Part 6 [24], specific gravity in accordance with IS2720:Part 3 [25], grain size distribution in accordance with IS2720:Part 4 [26], compaction characteristics in accordance with IS2720:Part 7 [27], free swell index in accordance with IS720:Part 40 [28] and UCS in accordance with IS2720:Part 10 [29]. The soil as well as the solid waste materials were also subjected to chemical, mineral and microstructural characterization. The soil was stabilized with 3\% lime for improving its properties. Bell [30] stated that 1-3\% lime content was sufficient to stabilize most of the soils. The lime stabilized soil was amended with various randomly selected doses of BA and CSP $(0.25 \%, 0.5 \%, 1 \%$ and $2 \%)$ to study the effect of amending lime stabilization with solid wastes. The lime stabilized soil was adopted as control for studying the effects of solid waste amendment. The lime stabilized soil as well as amended specimens were subjected to curing for 28 days before the tests were conducted. The stabilized soil samples were subjected to UCS, Atterberg limits and free swell index tests and the results were compared. The stabilized soil specimens were also subjected to microstructural analysis to perceive the changes in the soil structure. The methodology has been adopted from earlier works [31, 32]. 


\section{Results and discussion}

The results of the UCS, plasticity and swell-shrink investigations have been discussed in the following sections.

\subsection{Effect of solid wastes on the plasticity of lime stabilized soil}

Figure 3 shows the effect of BA on the plasticity of $3 \%$ lime stabilized soil. It can be seen that the addition of BA results in a significant modification in liquid limit of the soil and a noticeable alteration in plastic limit of the soil, resulting in the modification of soil plasticity. Addition of $0.25 \%$ BA results in a significant reduction in liquid limit from $63.76 \%$ to $55.44 \%$ but thereafter further addition of BA results in an increase in liquid limit of the soil. The liquid limit increase stabilizes above $1 \%$ addition of BA. In the case of plastic limit, $0.25 \%$ BA addition raises the plastic limit to $34.63 \%$ from $32.56 \%$ for pure lime stabilized soil. On further increasing the BA content, there is a slight reduction in plastic limit till $2 \%$ addition. The combined effect on the plasticity of the soil can be seen in the form of a reduction in plasticity of close to $11 \%$ at $0.25 \%$ BA dosage. The plasticity drops from $31.2 \%$ to $20.81 \%$ for BA dosage mentioned above. However, any further increase in BA dosage increases the plasticity, but still it is lesser than the plasticity of pure lime stabilized soil.

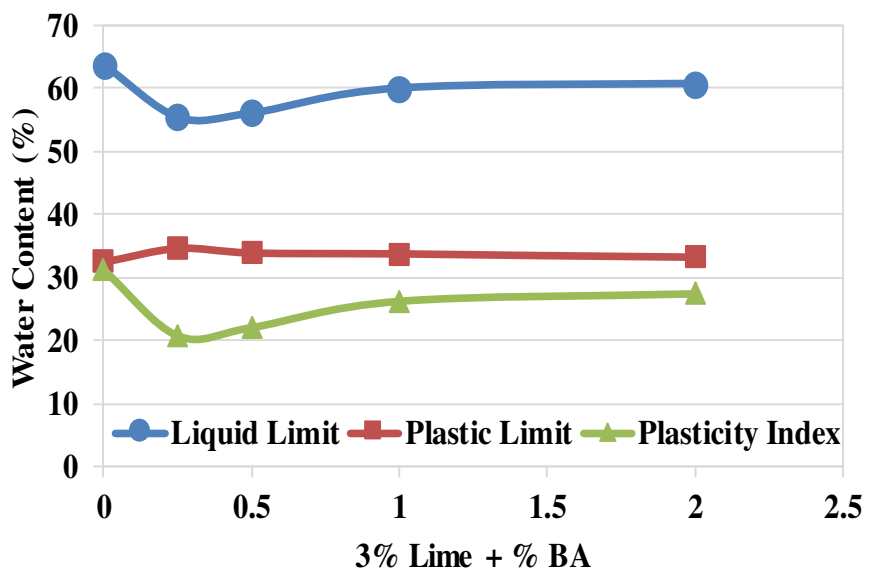

Figure 3: Effect of BA on the Plasticity of 3\% Lime Stabilized Soil

Manikandan and Moganraj [8] also reported that optimal addition of BA to 3\% lime stabilized soil reduced plasticity but further increase in the BA content resulted in an increase in the plasticity of the soil. Muazu [33] found that addition of BA to cement stabilization further aided the aggregation and flocculation of the clay particles leading to a reduction in liquid limit of the soil. Manikandan and Moganraj [8] also cited flocculation-aggregation due to ion exchange as reason for reduction in plasticity of BA amended lime stabilized expansive soil. Wubshet [34], in his study, states that significant reduction in plasticity due to addition of BA in combination with lime is due to more availability of calcium for ion exchange and partial replacement of plastic soil particles with non-plastic BA particles. Moreover, BA is also rich 
in silica, which also contributes to pozzolanic interactions leading to alteration in soil structure resulting in altered plasticity.

The effect of addition of CSP on the plasticity of lime stabilized soil is shown in Figure 4. The addition of CSP to $3 \%$ lime stabilized soil results in a reduction in liquid limit of the stabilized soil until $0.5 \%$ dosage of CSP. The liquid limit reduces from $63.76 \%$ to $58.33 \%$ for $0.5 \%$ CSP addition. Further increase in the CSP content results in increase in liquid limit of the stabilized soil, however, it stabilizes beyond 1\% addition of CSP. The plastic limit of the stabilized soil increases on addition of $0.25 \%$ CSP which then reduces on further increase in CSP content and becomes more or less stable above $0.5 \%$ CSP content. The plastic limit increases from $32.56 \%$ to $37.74 \%$ for $0.25 \%$ addition of CSP. The effect of these changes can be seen as a significant drop in the plasticity of the stabilized soil at $0.25 \%$ CSP content. The plasticity of $3 \%$ lime stabilized soil reduces significantly from $31.2 \%$ to $22.08 \%$ beyond which the plasticity increases steadily till $2 \%$ CSP addition to $25.86 \%$. A look at the composition of CSP clearly reveals silica as a major component, which can contribute to pozzolanic activity taking place between soil and lime. However, the organic nature of CSP may be responsible for the detrimental effects seen in consistency limits. Huang et al. [35] state that organic matter in soil increases both liquid and plastic limits but water adsorption capacity of organic matter exceeds the reduction in limits caused by organic matter induced aggregation of soil. Puppala et al. [36] found that addition of organic dairy manure compost to soil resulted in a reduction in plasticity of the amended soil whereas biosolids compost amendment resulted in an increase in plasticity, which they attributed to variations in hydrophilic organic content and cation exchange capacity.

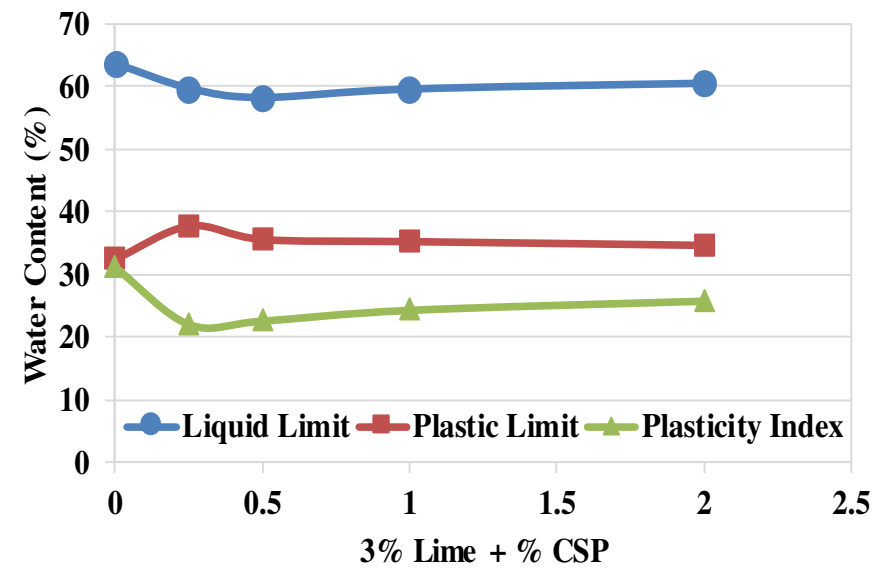

Figure 4: Effect of CSP on the Plasticity of 3\% Lime Stabilized Soil

\subsection{Effect of solid wastes on the classification of lime stabilized soil}

Figure 5 indicates the plots of the position of lime-BA stabilized soil combinations on the plasticity chart. It is revealed that the addition of BA to $3 \%$ lime stabilized soil goes a long way in changing the classification of the soil. Addition of lime alone brings it just below the A-line whereas the addition of BA to it, results in significant move towards intermediate 
plasticity at $0.25 \% \mathrm{BA}$ addition. A clear look at the plots of the various combinations on the plasticity chart is enough to understand that CSP produces beneficial movement of the points on the chart in the case of $3 \%$ lime stabilized soil wherein the addition of CSP resulted in the movement of the plot points leftward and downwards when compared to the control lime stabilized soil.

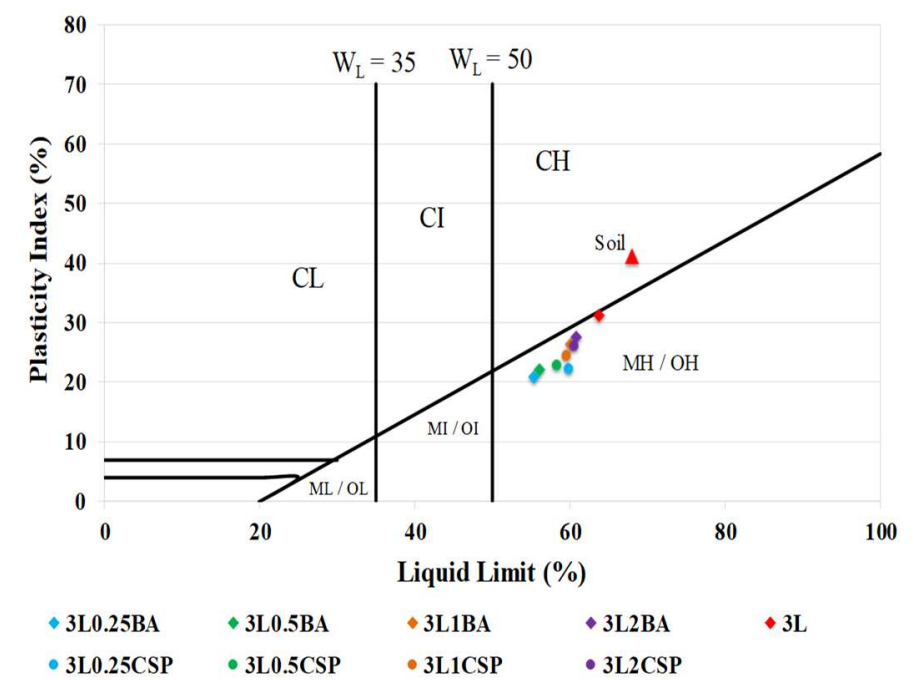

Figure 5: Location of Lime-Solid Waste Stabilized Soil on Plasticity Chart

\subsection{Effect of solid wastes on the swell-shrink of lime stabilized soil}

Free swell of lime stabilized soil amended with BA and CSP is represented in Figure 6. The addition of BA to $3 \%$ lime stabilized soil results in a reduction in free swell of the stabilized soil. The swell of 3\% lime stabilized soil reduced initially from $50 \%$ to $33.33 \%$ for addition of $0.5 \%$ BA, but increased on further increase in BA content to $39.39 \%$ for $2 \%$ BA. Sabat [37] alludes to the pozzolanic reactions of silica and alumina present in BA and soil with lime as reason for the reduction in swell pressure of the stabilized soil. Wubshet [34] cites cation exchange and flocculation as responsible phenomena for reduction in swell of the stabilized soil along with reduction in expansive clay fines due to their replacement by BA.

At 3\% lime-stabilized soil, addition of CSP reduces swell initially but raises swell on further increase in CSP content of the stabilized soil. The swell reduces to $45 \%$ from the control value of $50 \%$ for $0.25 \%$ CSP amendment. Thereafter, swell increases to $57.5 \%$ for $2 \%$ CSP addition. The organic nature of CSP may be responsible for the increase in swell with increased CSP content. James and Pandian [38] found that addition of organic tamarind kernel powder to soil for stabilization purposes resulted in an increase in free swell of the soil. 


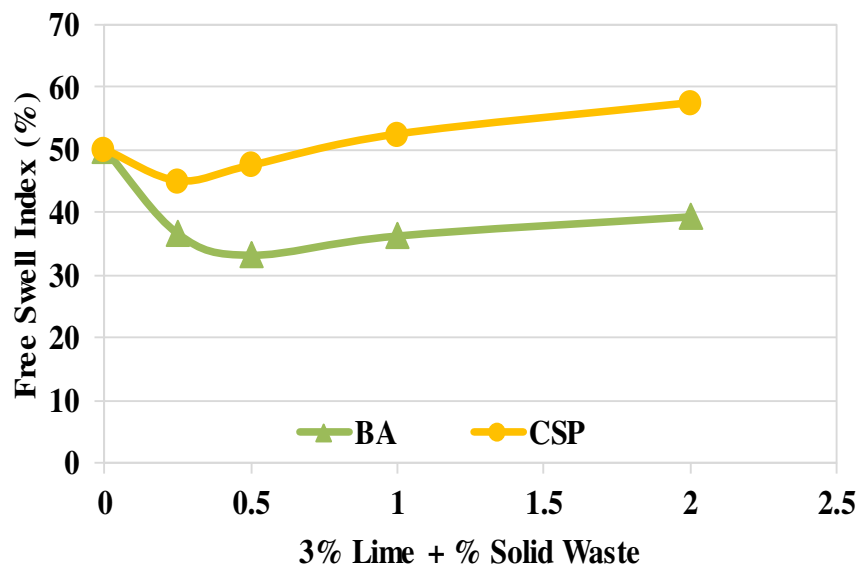

Figure 6: Effect of Solid Wastes on Swell of 3\% Lime Stabilized Soil

The effect of BA and CSP on the shrinkage limit of the stabilized soil is displayed in Figure 7. It is evident that addition of BA results in an increase in shrinkage limit of the lime stabilized soil. It can be seen that increase in shrinkage limit is steep till $0.5 \%$ BA addition beyond which the increment stabilizes and the variation stays flat. The shrinkage limit increases from $17.31 \%$ to $23.76 \%$ at $1 \%$ BA addition for $3 \%$ lime stabilization. Schettino and Holanda [18] found that partial replacement of quartz with $1.25 \%$ optimal BA content reduced the linear shrinkage of ceramic tiles. Dang et al. [12] found that $25 \%$ addition of combinations of limeBA in 1:3 ratio resulted in an $83.5 \%$ reduction in linear shrinkage when compared to $64 \%$ reduction achieved by pure lime alone. It is plain that addition of CSP results in a reduction in shrinkage limit of the lime stabilized soil for lime content of 3\%. The shrinkage limit of the lime stabilized soil amended with CSP steadily decreased from $17.31 \%$ to $14.5 \%$ for increase in CSP addendum to $2 \%$.

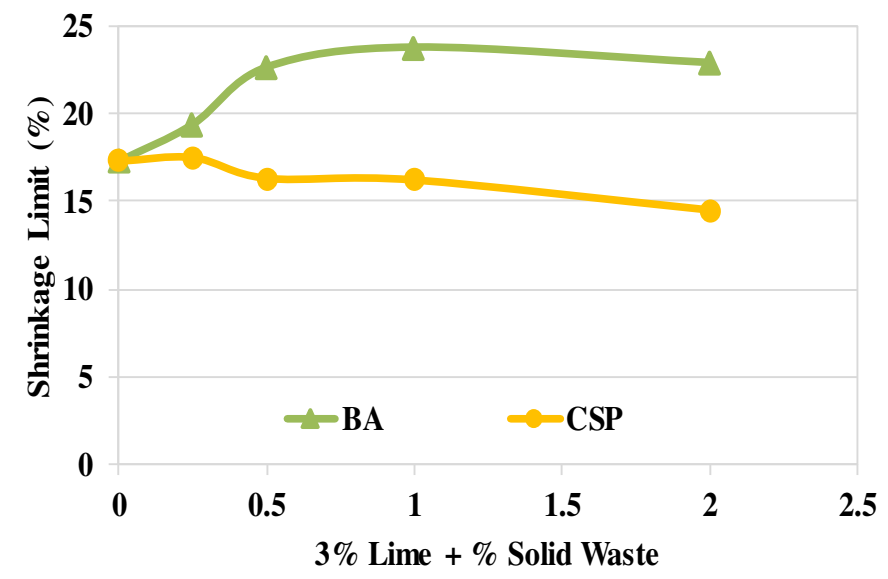

Figure 7: Effect of Solid Wastes on Shrinkage Limit of 3\% Lime Stabilized Soil 


\subsection{Effect of solid wastes on the UCS of lime stabilized soil}

The UCS tests were conducted on the lime stabilized and amended specimens after 28 days of curing. Figure 8 shows the comparison of 28-day strength of lime stabilized soil amended with BA and CSP. It can be clearly seen that the addition of BA is beneficial to lime stabilization of soil with a further increase in strength of the stabilized soil whereas the addition of CSP resulted in a reduction in strength of the stabilized soil. Thus, strength tests also reinforce BA to be a better auxiliary additive when compared to CSP for lime stabilization. It can be seen that addition of BA to lime stabilized soil results in an increase in strength at $0.25 \%$ addition of BA. The addition of $0.25 \%$ BA to $3 \%$ lime has resulted in the strength increasing from $547.48 \mathrm{kPa}$ to $677.25 \mathrm{kPa}$ at 28 days of curing which is a $23.7 \%$ gain in strength when compared to pure lime stabilization. Thus, it can be seen that addition of BA to lime in stabilization of expansive soil is capable of improving the strength of even lime stabilized soil. Sadeeq et al. [39] also reported an increase in UCS of the stabilized soil for upto $6 \%$ addition of BA to different lime contents upto 8\%. Dang et al. [12] also reported a significant increase in UCS when lime and BA were used in the ratio 1:3 for stabilization of an expansive soil. Addition of CSP, however, to $3 \%$ lime stabilization of soil results in a negative impact on the strength of the stabilized soil. There is a significant drop in the strength on addition of CSP, however, the strength variation between the various CSP amended samples is minimal. At 28 days of curing, the strength of the lime stabilized soil amended with CSP varies from $497.47 \mathrm{kPa}$ to $483.18 \mathrm{kPa}$ for various additions of CSP against $547.48 \mathrm{kPa}$ for pure lime stabilization. Thus, addition of CSP to $3 \%$ lime stabilized soil results in an average reduction of $10.5 \%$ in strength of the stabilized soil. Jamgade et al. [15] reported an increase in CBR when 4\% CSP was added to flyash and cement for stabilizing the soil.

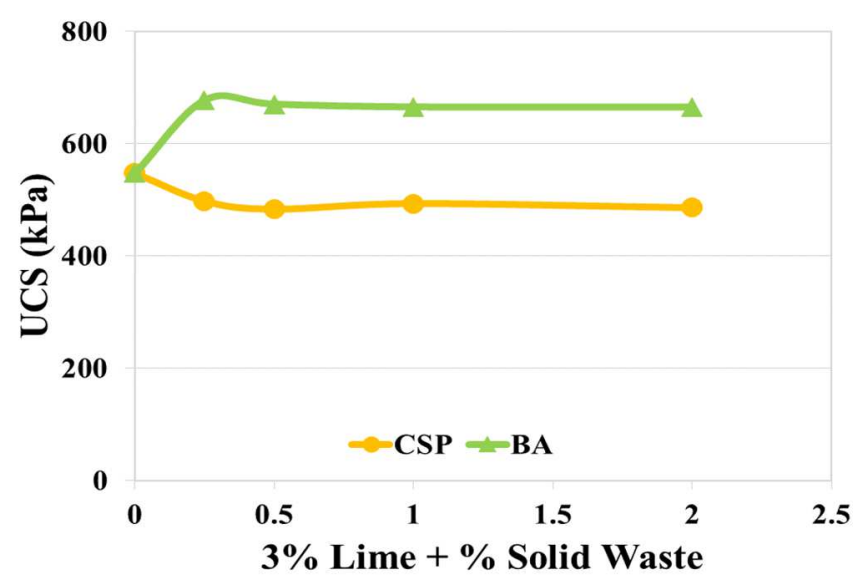

Figure 8: 28-Day UCS of 3\% Lime Stabilized Soil Amended with Solid Wastes

\subsection{Effect of solid wastes on the microstructure of lime stabilized soil}

The amended stabilized soil samples were subjected to microstructural investigations. Based on the plasticity, swell-shrink characteristics and UCS, $0.25 \%$ BA and CSP amended lime 
stabilized soil samples were selected for the microstructural study. Figure 9 shows the microstructure of $3 \%$ lime stabilized soil. It can be seen that the addition of $3 \%$ lime has resulted in the formation of a dense mass of soil. The individual plate like textures noticed on the clay lumps in the microstructure of the soil cannot be seen. This is due to the destruction of the microstructure during lime stabilization to form pozzolanic products. Muhmed and Wanatowski [40] also reported aggregation of soil particles due to lime treatment of kaolin clay as revealed by SEM studies. Al-mukhtar et al. [41] reported the formation of a dense compact mass due to stabilization of an expansive soil with lime. However, unreacted chunks of soil particles are also seen in the microstructure.

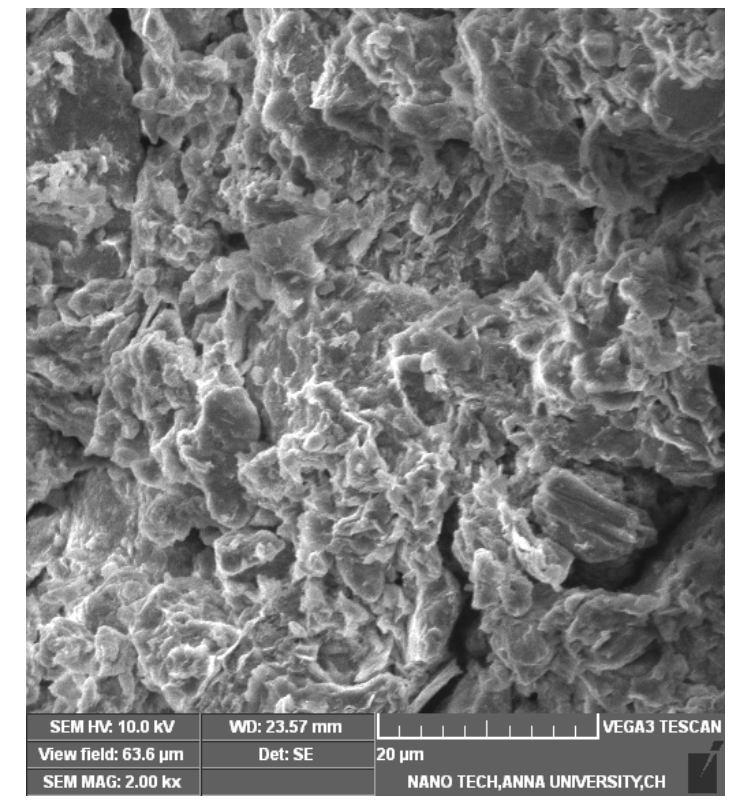

Figure 9: Microstructure of 3\% Lime Stabilized Soil

Figure 10 shows the microstructure of lime stabilized soil amended with $0.25 \%$ BA. It can be clearly seen that there is marked difference in the appearance of the microstructure of the stabilized soil with and without BA. The addition of BA has resulted in the formation of a denser microstructure with a more uniform distribution of leaf like formations indicating the formation of hydration products of pozzolanic reactions. However, it can also be noted that few unreacted lumps of soil particles can also be seen sparsely distributed in the field of view. Figure 11 shows the microstructure of lime stabilized soil amended with $0.25 \%$ CSP. It is evident that the addition of CSP has resulted in a modified microstructure of the stabilized soil. The microstructure, though appears to be dense, there seems to be much lesser aggregation of the soil when compared to either of the earlier micrographs. The leaf like pozzolanic products that are seen in the earlier two micrographs seem to be much smaller and sparser in the microstructure of CSP amended stabilized soil. Moreover, there seems to large zones of unreacted soil with clay platelets dispersed throughout the field of view. This may be indicative of a slower progress of pozzolanic reactions as evident from UCS with lesser strength due to CSP amendment at 28 days of curing. 


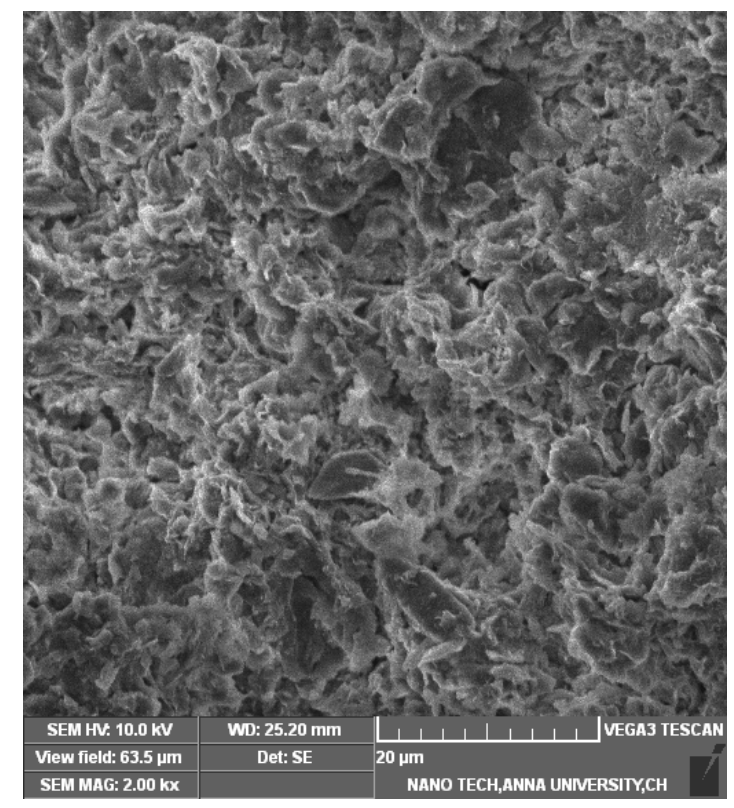

Figure 10: Microstructure of 3\% Lime Stabilized Soil amended with BA

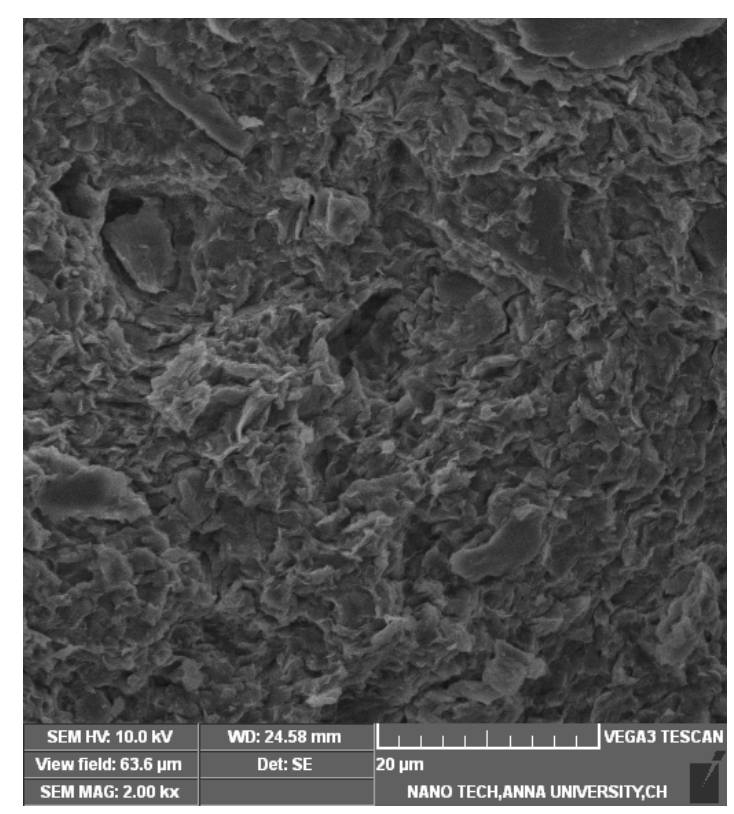

Figure 11: Microstructure of 3\% Lime Stabilized Soil amended with CSP

\section{Conclusion}

Based on the investigation conducted on the utilization of solid wastes in amendment of lime soil stabilization, the following points may be concluded.

(i) Addition of BA to lime stabilization of soil resulted in a reduction in plasticity of the stabilized soil by reducing its liquid limit and increasing its plastic limit. However, the reduction in plasticity was only achieved at low dosages of BA with plasticity increasing 
with higher doses of BA. The influence of BA was more on liquid limit when compared to plastic limit. $0.25 \%$ BA was found to achieve the lowest plasticity of the stabilized soil.

(ii) Addition of CSP to lime stabilized soil also resulted in a reduction in plasticity similar to BA, but the reduction achieved by CSP was not as much as that of BA. The influence of CSP was more on plastic limit when compared to liquid limit. CSP also was able to achieve reduction in plasticity only at low doses. $0.25 \%$ CSP was found to achieve the maximum reduction in plasticity.

(iii) Addition of BA was able to achieve better swell control when compared to CSP. Both BA and CSP were able to reduce swell at low doses of $0.25 \%$ whereas BA reduced swell even at $0.5 \%$ addition. However, further increase in solid waste dosage resulted in an increase in swell of the stabilized soil. But, increase in swell in BA amended soil was below that of the swell of pure lime stabilized soil whereas CSP addition resulted in swell increasing above the swell achieved by pure lime stabilized soil. Thus, BA produced better swell control compared to CSP.

(iv) Addition of BA resulted in an increase in shrinkage limit of the lime stabilized soil whereas the addition of CSP resulted in a decrease in the shrinkage limit of the soil beyond $0.25 \%$ addition. The increase in shrinkage limit of the soil was higher till $0.5 \%$ addition beyond which the variation was minimal. In the case of CSP, the reduction in shrinkage limit of the soil was marginal till $0.25 \%$ beyond which there was a clear reduction. Thus, BA was better in improving the shrink nature of the soil compared to CSP.

(v) Addition of BA as auxiliary additive to lime resulted in a further increase in the UCS of the stabilized soil whereas CSP resulted in a reduction in strength. BA was capable of achieving a $23.7 \%$ increase in strength over pure lime stabilization whereas CSP resulted in a $10.5 \%$ loss in strength on an average.

(vi) The microstructure of BA amended lime stabilized soil showed better aggregation and compactness compared to CSP amended lime stabilized soil. Moreover, the former revealed a better progress of pozzolanic reaction leading to formation of reaction products compared to the latter.

(vii) Based on the investigation conducted, up to $0.5 \% \mathrm{BA}$ can be considered as optimal amendment dosage for 3\% lime stabilized expansive soil. However, more detailed investigations need to be conducted with regards to CSP with other soil types and properties before recommending it in soil stabilization.

Finally, it can be concluded that BA amendment of lime stabilized soil is a better alternative to CSP amendment of lime stabilized soil and BA can be preferred as an auxiliary additive to lime-soil stabilization over CSP.

\section{Acknowledgements}

The authors thank the management of Tagore Engineering College for providing the laboratory facilities for carrying out this investigation. The authors gratefully acknowledge the XRF facility provided by SAIF, IIT Bombay, Mumbai India and XRD \& SEM facility provided by Anna University, Chennai. The authors would also like to thank Mr. M. Sasi Kumar, Laboratory Instructor, Soil Engineering Laboratory, Tagore Engineering College and Students of B.E., Civil Engineering for helping out with the testing work. 


\section{References}

[1] Transport Research Laboratory. (2003). Literature Review:Stabilised Sub-Bases for Heavily Trafficked Roads. Berkshire, UK. Retrieved from http://www.transportlinks.org/transport_links/filearea/documentstore/106_Literature Review Stabilised subbases.pdf

[2] James, J., \& Pandian, P. K. (2016). Industrial Wastes as Auxiliary Additives to Cement / Lime Stabilization of Soils. Advances in Civil Engineering, 2016(Article ID 1267391), 1-17. doi:doi.org/10.1155/2016/1267391

[3] Osinubi, K. J., Bafyau, V., \& Eberemu, A. O. (2009). Bagasse Ash Stabilization of Lateritic Soil. In E. K. Yanful (Ed.), Appropriate Technologies for Environmental Protection in the Developing World (pp. 281-290). Springer Science. doi:10.1007/9781-4020-9139-1

[4] Chittaranjan, M., Vijay, M., \& Keerthi, D. (2011). Agricultural wastes as soil stabilizers. International Journal of Earth Sciences and Engineering, 4(06 SPL), 5051 .

[5] Anupam, A. K., Kumar, P., \& Ransinchung R N, G. D. (2013). Use of Various Agricultural and Industrial Waste Materials in Road Construction. Procedia - Social and Behavioral Sciences, 104, 264-273. doi:10.1016/j.sbspro.2013.11.119

[6] Salim, R. W., Ndambuki, J. M., \& Adedokun, D. A. (2014). Improving the Bearing Strength of Sandy Loam Soil Compressed Earth Block Bricks Using Sugarcane Bagasse Ash. Sustainability, 6(6), 3686-3696. doi:10.3390/su6063686

[7] Ijimdiya, T. S., \& Osinubi, K. J. (2011). Attenuative Capacity of Compacted Black Cotton Soil treated with Bagasse Ash. Electronic Journal of Geotechnical Engineering, 16(Bund D), 419-429.

[8] Manikandan, A. T., \& Moganraj, M. (2014). Consolidation and Rebound Characteristics of Expansive Soil by Using Lime and Bagasse Ash. International Journal of Research in Engineering and Technology, 3(4), 403-411.

[9] Osinubi, K. J., Ijimdiya, T. S., \& Nmadu, I. (2009). Lime Stabilization of Black Cotton Soil Using Bagasse Ash as Admixture. Advanced Materials Research, 62, 3-10. doi:10.4028/www.scientific.net/AMR.62-64.3

[10] Khobklang, P., Nokkaew, K., \& Greepala, V. (2008). Effect of Bagasse Ash on Water Absorption and Compressive Strength of Lateritic Soil Interlocking Block. In M. C. Limbachiya \& H. Y. Kew (Eds.), Proceedings of the International Conference on Excellence in Concrete Construction Through Innovation, 9 - 10 September (pp. 181185). Kingston upon Thames, United Kingdom.

[11] James, J., \& Pandian, P. K. (2016). Valorisation of Sugarcane Bagasse Ash in Manufacture of Lime-Stabilized Blocks. Slovak Journal of Civil Engineering, 24(2), 715. doi:10.1515/sjce-2016-0007

[12] Dang, L. C., Hasan, H., Fatahi, B., \& Khabbaz, H. (2015). Influence of Strength and Mechanical Behaviour of Bagasse Ash and Hydrated Lime Stabilized Expansive Soil. In GEOQuebec 2015 - Chall. from North to South, 20- 23 September. Quebec, Canada. 
[13] Dang, L. C., Hasan, H., Fatahi, B., Jones, R., \& Khabbaz, H. (2016). Enhancing the Engineering Properties of Expansive Soil Using Bagasse Ash and Hydrated Lime. International Journal of GEOMATE, 11(25), 2447-2454.

[14] Shabana, S. K., Anshi, C., Shamsheera, P., Shyamili, T. M., Sruthi, V., \& Suhaira, P. (2014). Study on CBR Values of Soil with Crushed Coconut Shells. International Journal of Advanced Engineering Technology, 5(3), 55-58.

[15] Jamgade, M., Charhate, S., \& Sinha, M. (2016). Experimental Study on Fly Ash, Cement and Coconut Shell Powder for Stabilization of Soil. International Journal of Global Technology Initiatives, 5(1), C28-C35.

[16] Arathy, V. B., Jery, C., Raj, J., Lekshmi, V. S., \& Chacko, A. (2015). Effect of Coconut Shell Powder on the Strength of Soil. International Journal of Management, Information Technology and Engineering, 3(2), 35-40.

[17] Torres Agredo, J., de Gutiérrez, R. M., Escandón Giraldo, C. E., \& González Salcedo, L. O. (2014). Characterization of sugar cane bagasse ash as supplementary material for Portland cement . Ingenieria e Investigacion, 34(1), 5-10. Retrieved from http://www.scopus.com/inward/record.url?eid=2-s2.084902179615\&partnerID=40\&md5=dc4743976baee14f0afade35b46291a8

[18] Schettino, M. A. S., \& Holanda, J. N. F. (2015). Characterization of Sugarcane Bagasse ash Waste for Its Use in Ceramic Floor Tile. Procedia Materials Science, 8, 190-196. doi:10.1016/j.mspro.2015.04.063

[19] Rodriguez-Diaz, J. M., Garcia, J. O. P., Sanchez, L. R. B., da Silva, M. G. C., da Silva, V. L., \& Arteaga-Perez, L. E. (2015). Comprehensive Characterization of Sugarcane Bagasse Ash for Its Use as an Adsorbent. Bioenergy Research, 8(4), 1885-1895. doi:10.1007/s12155-015-9646-6

[20] Bahurudeen, A., Wani, K., Basit, M. A., \& Santhanam, M. (2015). Assesment of Pozzolanic Performance of Sugarcane Bagasse Ash. Journal of Materials in Civil Engineering, 28(2001), 4015095. doi:10.1061/(ASCE)MT.1943-5533.0001361

[21] James, J., \& Pandian, P. K. (2017). A Short Review on the Valorisation of Sugarcane Bagasse Ash in the Manufacture of Stabilized / Sintered Earth Blocks and Tiles. Advances in Materials Science and Engineering, 2017(AID 1706893), 1-15.

[22] BIS. IS 2720 Methods of Test For Soils:Part 1 - Preparation of Dry Soil Sample for Various Tests (1983). India.

[23] BIS. IS 2720 Methods of Test for Soils:Part 5 Determination of Liquid and Plastic Limit (1985). India.

[24] BIS. IS 2720 Methods of Test for Soils:Part 6 Determination of Shrinkage Factors (1972). India.

[25] BIS. IS 2720 Methods of Test for Soils Part 3:Determination of Specific Gravity/Section 1 Fine Grained Soils (1980). India.

[26] BIS. IS 2720 Methods of Test for Soils:Part 4 Grain Size Analysis (1985). India.

[27] BIS. IS 2720 Methods of Test for Soils:Part 7 Determination of Water Content-Dry 
Density Relation Using Light Compaction (1980). India.

[28] BIS. IS 2720 Methods of Test for Soils:Part 40 Determination of Free Swell Index of Soils (1977). India.

[29] BIS. IS 2720 Methods of Test for Soils:Part 10 - Determination of Unconfined Compressive Strength (1991). India.

[30] Bell, F. G. (1996). Lime stabilization of clay minerals and soils. Engineering Geology, 42(4), 223-237. doi:10.1016/0013-7952(96)00028-2

[31] James, J., \& Pandian, P. K. (2016). Plasticity, Swell-Shrink and Microstructure of Phosphogypsum Admixed Lime Stabilized Expansive Soil. Advances in Civil Engineering, 2016(Article ID 9798456), 1-10.

[32] James, J., \& Pandian, P. K. (2014). Effect of Phosphogypsum on Strength of Lime Stabilized Expansive Soil. Gradevinar, 66(12), 1109-1116. doi:10.14256/JCE.1097.2014

[33] Muazu, M. A. (2007). Evaluation of Plasticity and Particle Size Distribution Characteristics of Bagasse Ash on Cement Treated Lateritic Soil. Leonardo Journal of Sciences, 10(1), 137-152.

[34] Wubshet, M. (2013). Bagasse ash as a Sub-grade Soil Stabilizing Material. M.S. Thesis. Addis Ababa Institute of Technology.

[35] Huang, P.-T., Patel, M., Santagata, M. C., \& Bobet, A. (2009). Classification of Organic Soils. $\quad$ Retrieved from http://docs.lib.purdue.edu/cgi/viewcontent.cgi?article=2676\&context=jtrp

[36] Puppala, A. J., Pokala, S. P., Intharasombat, N., \& Williammee, R. (2007). Effects of Organic Matter on Physical, Strength, and Volume Change Properties of Compost Amended Expansive Clay. Journal of Geotechnical and Geoenvironmental Engineering, 133(11), 1449-1461.

[37] Sabat, A. K. (2012). Utilization of Bagasse Ash and Lime Sludge for Construction of Flexible Pavements in Expansive Soil Areas. Electronic Journal of Geotechnical Engineering, 17(Bund. H), 1037-1046.

[38] James, J., \& Pandian, P. K. (2013). Performance Study on Soil Stabilisation using Natural Materials. International Journal of Earth Sciences and Engineering, 6(1), 194203.

[39] Sadeeq, J. A., Ochepo, J., Salahuddin, A. B., \& Tijjani, S. T. (2015). Effect of Bagasse Ash on Lime Stabilized Lateritic Soil. Jordan Journal of Civil Engineering, 9(2), 203213.

[40] Muhmed, A., \& Wanatowski, D. (2013). Effect of Lime Stabilisation on the Strength and Microstructure of Clay. IOSR Journal of Mechanical and Civil Engineering, 6(3), 87-94.

[41] Al-Mukhtar, M., Khattab, S., \& Alcover, J. (2012). Microstructure and geotechnical properties of lime-treated expansive clayey soil. Engineering Geology, 139, 17-27. doi:10.1016/j.enggeo.2012.04.004 